\title{
Factors associated with HIV infection are not the same for all women
}

\author{
E V Boisson, L C Rodrigues
}

J Epidemiol Community Health 2002;56:103-108

See end of article for authors' affiliations .....................

Correspondence to: Dr E V Boisson, Caribbean Epidemiology Centre, 16-18 Jamaica Boulevard, Federation Park, Port of Spain, Trinidad, West Indies;

boissoel@carec.paho.org

Accepted for publication 3 July 2001
Study objectives: To determine if factors associated with HIV infection vary between subpopulations of women resident in Great Britain.

Design: Case-control analyses on already existing datasets.

Setting: Great Britain.

Participants: 317 cases selected from a MRC Collaborative Study of HIV Infection in Women and 3635 controls selected from a National Survey of Sexual Attitudes and Lifestyles.

Main results: Factors associated with HIV infection varied among subpopulations of women. Among women heterosexually infected, factors associated with HIV infection were residence in London lodds ratio $(O R)=8.3 ; 95 \%$ confidence intervals $(\mathrm{Cl}) 4.6$ to 14.9$)$, widowhood $(\mathrm{OR}=47.6 ; \mathrm{Cl} 20.0$ to 113.1), being black $(O R=25.2 ; \mathrm{Cl} 15.6$ to 40.8$)$ and particularly among white women, having 10 or more sexual partners $(O R=14.5 ; \mathrm{Cl} 5.1$ to 41.3$)$. Young age was important for black women heterosexually infected. Among women who shared needles, residence in London $(O R=19.0 ; \mathrm{Cl} 5.8$ to 62.6) or Scotland (OR $=26.9 ; \mathrm{Cl} 8.0$ to 90.4) and large numbers of sexual partners was important $(O R=19.6 ; \mathrm{Cl} 6.4$ to 60.0$)$; termination of pregnancy history was also important for those with fewer than 10 sexual partners $(\mathrm{OR}=6.7 ; \mathrm{Cl} 3.4$ to 13.1$)$; and low social class was important for those with 10 or more sexual partners (OR $=4.1 ; \mathrm{Cl} 1.7$ to 9.6$)$.

Conclusions: Factors vary in importance and significance of association with HIV infection in different subpopulations of women resident in Great Britain. This diversity is also likely to occur in other populations. It is important to identify these differences between subpopulations. Prevention and control policies and activities for HIV/AIDS cannot treat all women as if they were the same. l: $\mathrm{n}$ the UK, as in the rest of the world, a growing proportion of women is becoming infected with HIV. In the UK, the rate of increase in newly diagnosed and reported HIV infections among women is rising, in 1994 it was 50\% higher for women than for men. ${ }^{12}$ Seroprevalence studies in Europe have shown an increasing HIV incidence among women. ${ }^{3}$ Of the three HIV transmission modes for women (heterosexual transmission, injecting drug use and the transfer of infected blood or blood products), heterosexual transmission accounts for the majority of HIV infections, with $78 \%$ of all reported HIV infections in women in the UK to March 1998 acquired this way. ${ }^{1}$ Also, in 1998, among heterosexually infected people in the UK, the majority $(53 \%)$ were black African. ${ }^{4}$ Heterosexual transmission is also important among injecting drug users (IDUs). Most female IDUs have more than one risk factor for HIV infection, ${ }^{5-8}$ as their drug use often puts them at risk of HIV infection directly (for example, via needle sharing) and indirectly (for example, via sex with a male IDU or sex for money or drugs). Some argue that these women are at greater risk as a result of heterosexual transmission than via needle sharing. ${ }^{58}$

This paper investigates factors associated with HIV infection in women aged 20-59 years resident in Great Britain, by analysing data collected for other purposes. These factors are expected to be of three types, those that lead to greater risk of infection, those that identify high HIV risk groups but do not in themselves lead to greater risk and those that are likely to be effects of infection. These three types of factors are all useful in identifying subpopulations of women at risk of HIV infection.

\section{METHODS}

\section{Datasets used}

Case-control analysis of secondary data was carried out on a study population consisting of cases selected from a cohort of
HIV infected women, the MRC Collaborative Study of HIV Infection in Women and controls selected from women in a population survey, the National Survey of Sexual Attitudes and Lifestyles. These two surveys are briefly described below, as design and methodology details have been given elsewhere. ${ }^{10-12}$

The MRC Collaborative Study of HIV Infection in Women consists of 505 HIV positive women recruited from 15 genitourinary medical centres in Britain and Ireland between June 1992 and August 1994. The geographical distribution of the centres reflects the spread of HIV infection in women in the UK, with 10 of the centres in London, three in other parts of SE England, one in Edinburgh and one in Dublin. All HIV positive women over the age of 18 years who were available for follow up visits were eligible for the study and written informed consent was obtained from all participants. Questionnaires were completed by investigators with data collected from face to face interviews and laboratory results. The data collected included personal background, sexual activity, obstetric history and probable route of HIV infection. Data on the probable route of HIV infection were derived in a hierarchical manner. Firstly, IDUs who had shared needles, either directly or indirectly, were classified as being infected via injecting drug use. Then women who could have been infected heterosexually, but had never shared needles were classified as being infected via sex. Injectors who had not shared needles were included in this group. Infected blood products was selected as the transmission mode for women who were definitely infected by needle stick injuries or had had transfusions between 1975 and 1985, had not shared needles and could not have been infected heterosexually. ${ }^{12}$ Social class was determined by the woman's longest held occupation, whether she was currently employed or not, according to the register general's classification. 
To determine how representative cases in the analyses are of all HIV positive women in the general population, a comparison was done between women from the MRC Collaborative Study of HIV Infection in Women and HIV reports (from voluntary testing) for women in Great Britain, as collected by the Communicable Disease Surveillance Centre (CDSC). ${ }^{13}$ A comparison was also done between the cases and CDSC AIDS case reports. ${ }^{13}$ AIDS case reports are likely to be more complete records of HIV infection in the population, as all HIV infections would eventually progress to AIDS, whereas HIV reports include only those HIV infected subjects who underwent an HIV test. Women who believe themselves to be at low risk of HIV infection (for example, women with one sexual partner) are less likely to test for HIV infection than those who believe themselves to be at high risk of HIV infection. However, because of the long average incubation period of HIV infection, AIDS case reports are made up of women infected some time earlier and are less likely to represent recent infections accurately.

The National Survey of Sexual Attitudes and Lifestyles (NATSSAL) was carried out between May 1990 and December 1991. A random sample of 8384 men and 10492 women aged 16-59 years, resident in Great Britain were selected from the Small Users Postcode Address File. ${ }^{10-14}$ Both interviewer completed and self completed (for the more sensitive questions) questionnaires were used to collect data on several variables including personal background, sexual experiences and termination of pregnancy history. The "social class" variable for women in this study was determined from her current and previous occupations within the last 10 years or her partner's social class, whichever was higher. ${ }^{10}$

\section{Study populations}

The study populations consisted of women selected from NATSSAL and the MRC Study. The women from these two studies who were included in the analyses were aged 20-59 years, resident in Great Britain and had all had unprotected heterosexual intercourse at some time in their lifetime, even though some women may have been celibate at the time of the survey. Four of the 505 women in the MRC study and 982 of the 10492 women in NATSSAL were outside of the $20-59$ years age range. Also, 570 of the women from NATSSAL never had a male sexual partner in their lifetime and thus were not included in the study population. Only women infected heterosexually or via needle sharing were selected from the MRC study, 29 women who were infected via blood transfer or had unknown modes of transmission were omitted from the analyses.

\section{Analysis}

Three case-control analyses of secondary data were done, each with a different group of women selected as cases, but using the same group of women as controls (table 1). In this paper the three analyses will be referred to as IDU, SEX and ALL. All the cases in the IDU analysis were exposed to both needle sharing and sex at the presumed time of infection, though they were not all necessarily IDUs at the time of the survey. The cases in the SEX analysis had never been IDUs and thus were only ever exposed to heterosexually transmitted HIV infection. The cases in the ALL analysis consisted of all women - that is, women who were ever IDUs and those who had never been IDUs. Women from NATSSAL were used as controls, assuming the vast majority to be HIV negative. This is a reasonable assumption, because in Great Britain HIV

Table 1 Composition of the study populations

\begin{tabular}{|c|c|c|c|c|}
\hline & \multicolumn{3}{|c|}{ Number of cases in analysis (\%) } & \multirow[b]{2}{*}{$\begin{array}{l}\text { Number of controls in } \\
\text { all three analyses (\%) } \\
\text { (that is, women from } \\
\text { NATSSAL) }\end{array}$} \\
\hline & $\begin{array}{l}\text { All } \\
\text { (that is, non-IDUs } \\
\text { and IDUs) }\end{array}$ & $\begin{array}{l}\text { Sex } \\
\text { (that is, non-IDUs) }\end{array}$ & $\begin{array}{l}\text { IDU } \\
\text { (that is, IDUs) }\end{array}$ & \\
\hline \multicolumn{5}{|l|}{ Age group } \\
\hline $20-24$ & $28(9)$ & $25(11)$ & $3(3)$ & $484(13)$ \\
\hline $25-29$ & $115(36)$ & $81(36)$ & $34(36)$ & 645 (18) \\
\hline $30-34$ & $99(31)$ & $70(31)$ & $29(31)$ & $558(15)$ \\
\hline $35-39$ & 40 (13) & $24(11)$ & $16(17)$ & $505(14)$ \\
\hline $40-59$ & $35(11)$ & $23(10)$ & $12(13)$ & $1443(40)$ \\
\hline \multicolumn{5}{|c|}{ Lifetime number of sexual partners } \\
\hline 1 & $19(6)$ & $15(7)$ & $4(4)$ & 1400 (39) \\
\hline 2 & $25(8)$ & $22(10)$ & $3(3)$ & $612(17)$ \\
\hline $3-4$ & $77(24)$ & $61(27)$ & $16(17)$ & $709(20)$ \\
\hline $5-9$ & $72(23)$ & $54(24)$ & 18 (19) & $561(15)$ \\
\hline $10+$ & 124 (39) & $71(32)$ & $53(56)$ & $354(10)$ \\
\hline \multicolumn{5}{|c|}{ Ever had a termination of pregnancy } \\
\hline No & $169(53)$ & $128(57)$ & $41(44)$ & 3048 (84) \\
\hline Yes & 148 (47) & $95(43)$ & $53(56)$ & $587(16)$ \\
\hline \multicolumn{5}{|l|}{ Marital status } \\
\hline Currently married* & $66(21)$ & $44(20)$ & $22(23)$ & $2317(64)$ \\
\hline Cohabiting & 61 (19) & $34(15)$ & $27(29)$ & $346(10)$ \\
\hline Widowed & $28(9)$ & 25 (11) & $3(3)$ & $76(2)$ \\
\hline Divorced & $19(6)$ & $10(5)$ & $9(10)$ & $215(6)$ \\
\hline Separated & $20(6)$ & $15(7)$ & $5(5)$ & $112(3)$ \\
\hline Never married & 123 (39) & $95(43)$ & $28(30)$ & $569(16)$ \\
\hline \multicolumn{5}{|l|}{ Social class } \\
\hline I-IIINM & $184(58)$ & $134(60)$ & $50(53)$ & $2446(67)$ \\
\hline IIIM-V & $83(26)$ & $50(22)$ & 33 (35) & $912(25)$ \\
\hline Other & $50(16)$ & $39(18)$ & $11(12)$ & $277(8)$ \\
\hline \multicolumn{5}{|l|}{ Area of residence } \\
\hline SE England $†$ & $18(6)$ & 15 (7) & $3(3)$ & $1708(47)$ \\
\hline London & $252(80)$ & $196(88)$ & $56(60)$ & $1062(29)$ \\
\hline Scotland & $47(15)$ & $12(5)$ & 35 (37) & $865(24)$ \\
\hline \multicolumn{5}{|l|}{ Ethnic group } \\
\hline White & $191(60)$ & $101(45)$ & $90(96)$ & 3390 (93) \\
\hline Black & $108(34)$ & $108(48)$ & $0(0)$ & $110(3)$ \\
\hline Asian & $6(2)$ & $6(3)$ & $0(0)$ & $95(3)$ \\
\hline Other & $12(4)$ & $8(4)$ & $4(4)$ & 40 (1) \\
\hline
\end{tabular}


Table 2 Odds ratio of being HIV positive when cases consisted of IDUs and non-IDUs

\begin{tabular}{|c|c|}
\hline & Adjusted odds ratio $\neq$ \\
\hline \multicolumn{2}{|l|}{ Age group } \\
\hline $20-24$ & $1.2(0.6$ to 2.3$)$ \\
\hline $25-29$ & $3.7(2.2$ to 6.2$) \dagger$ \\
\hline $30-34$ & $4.7(2.9$ to 7.8$) \dagger$ \\
\hline $35-39$ & $2.3(1.3$ to 4.1$) \dagger$ \\
\hline $40-59$ & 1.0 \\
\hline \multicolumn{2}{|c|}{ Lifetime number of sexual partners } \\
\hline 1 & 1.0 \\
\hline 2 & $1.6(0.8$ to 3.4$)$ \\
\hline $3-4$ & $4.4(2.4$ to 8.0$) \dagger$ \\
\hline $5-9$ & $7.1(3.8$ to 13.2$) \dagger$ \\
\hline $10+$ & $20.0(10.7$ to 37.2$) \dagger$ \\
\hline \multicolumn{2}{|c|}{ Ever had a termination of pregnancy } \\
\hline No & 1.0 \\
\hline Yes & $1.8(1.3$ to 2.4$) \dagger$ \\
\hline \multicolumn{2}{|l|}{ Marital status } \\
\hline Currently married§ & 1.0 \\
\hline Cohabiting & $2.3(1.5$ to 3.6$) \dagger$ \\
\hline Widowed & $22.6(10.8$ to 47.4$) \dagger$ \\
\hline Divorced & $1.8(1.0$ to 3.4$)$ \\
\hline Separated & $1.8(0.9$ to 3.5$)$ \\
\hline Never married & $2.0(1.3$ to 3.0$) \dagger$ \\
\hline \multicolumn{2}{|l|}{ Social class } \\
\hline I-IIINM & 1.0 \\
\hline$\| I M-V$ & $1.6(1.1 \text { to } 2.2)^{*}$ \\
\hline Other & $1.4(0.9$ to 2.3$)$ \\
\hline \multicolumn{2}{|l|}{ Area of residence } \\
\hline SE England $\mathbb{T}$ & 1.0 \\
\hline London & $9.7(5.7$ to 16.3$) \dagger$ \\
\hline Scotland & $6.7(3.7$ to 12.1$) \dagger$ \\
\hline \multicolumn{2}{|l|}{ Ethnic group } \\
\hline White & 1.0 \\
\hline Black & $15.8(10.3$ to 24.5$) \dagger$ \\
\hline Asian & $1.5(0.6$ to 3.7$)$ \\
\hline Other & $4.9(2.1$ to 11.5$) \dagger$ \\
\hline
\end{tabular}

Cases are 317 HIV positive women who: (1) engaged in high risk sex $=223$ women; (2) shared needles $=94$ women. * $p$ value $<0.05$ tp value $<0.005$; fadjusted for all the variables in the model; tp value $<0.005$; fadjusted for all the variables in the model;
$\S$ currently married and living with spouse; Iexcluding London.

prevalence is very low in women. In 1998, HIV prevalence among pregnant women was $0.22 \%$ in London, $0.015 \%$ elsewhere in the UK and 0.023 in Scotland. ${ }^{15}$ The variables investigated in the analyses were: age, lifetime number of sexual partners, termination of pregnancy history, marital status, area of residence, ethnic group and most probable HIV exposure category. Age, marital status, area of residence, termination of pregnancy history and lifetime number of sexual partners (male) were measured at entry to the study. Also, only cases with no missing values for all the variables were included in the analyses, thus using a complete model.

Odds ratios (ORs), used as a measure of relative risk, $95 \%$ confidence intervals and statistical significance tests for interactions were calculated from multiple logistic regression generated by the maximum likelihood method, using SPSS. ${ }^{16}$ These ORs were adjusted for all significant factors simultaneously to correct for the potential confounding effect of each factor. Mantel-Haenszel $\chi^{2}$ values were generated using Epi-Info, to make comparisons between age, exposure category and ethnic group distributions of the cases from the MRC Collaborative Study of HIV Infection in Women and these distributions in CDSC HIV and AIDS case reports. As HIV infection patterns have changed with time, the date of first positive HIV test was taken into account in these comparisons.

\section{RESULTS}

\section{Study populations}

The age and ethnic group distributions of the cases in the analyses were similar to that of all reported HIV positive women in equivalent geographical areas of Great Britain.
The study populations are presented in table 1 . The mean age of the controls was 37 years, while that of the IDU and SEX cases was 31 and 32 years respectively. The mean number of sexual partners for the controls was four, compared with 19 for the cases. Even when the medians are compared (considering that sex workers have rather large numbers of partners and will thus skew the distributions) there is still a marked difference, two for controls and six for cases. The mean and median numbers of sexual partners for the IDU cases were 31 and 10 respectively, compared with 14 and 5 for the SEX cases, because of the higher percentage of women with 10 or more partners among IDU cases. Most cases lived in London and SEX cases had the highest prevalence of widowhood. The social class distributions for cases and controls were similar. While the largest proportion of all cases were white, the largest percentage of cases in the SEX analysis were black (of whom $94 \%$ were black African and $6 \%$ black Caribbean).

\section{ALL infected women}

The adjusted odds ratios of being HIV positive for the ALL analysis are shown in table 2 . This analysis showed that with women considered as a single group, HIV infection was significantly associated with all the variables in the model.

\section{Women infected through SEX}

Table 3 shows the adjusted relative risk of being HIV positive for the analysis of cases who are at risk through sex only. Among this subpopulation of women, social class and termination of pregnancy history no longer showed a significant association with being HIV positive. Ethnic group showed a significant interaction with age, number of sexual partners and social class (table 3). Among black women, those in the younger age groups were at greater risk of HIV than among white women. However, among those who had 10 or more sexual partners, white women were at a significantly greater risk of HIV infection than black women of the same age. So women most likely to have been HIV infected via sex are those who are widowed, resident in London, black or have 10 or more partners. However, among women infected via sex, black women are likely to be younger and have fewer sexual partners than white women.

\section{Infected women who were ever IDUs}

The adjusted ORs for being HIV positive among those who were ever IDUs are given in table 4. Among this subpopulation of women, age and widowhood were not as strongly associated with being HIV positive as they were among all women and among those infected through sex. Number of lifetime sexual partners showed a significant interaction with termination of pregnancy. Among women who had a termination of pregnancy, those with fewer than 10 sexual partners were at a significantly greater risk of HIV infection than those with 10 or more partners. Among IDUs, HIV positive women are most likely to have had multiple sexual partners in their lifetime and be resident in either London or Scotland. Additionally, IDUs with fewer than 10 sexual partners are most likely to be either cohabiting or single and those with 10 or more partners are most likely to be in a manual social class.

\section{DISCUSSION}

HIV infection in women of reproductive age is increasing faster than in any other population group. However, until recently, this group has been relatively neglected in HIV research, viewed as "transmission vectors" to men and children. This paper compared factors associated with HIV infection among different subpopulations of women. However, some risk factors such as sex with an HIV positive partner or men in high risk groups, injecting drug use behaviours, condom use and sex for money or drugs could not be investigated, as the data were not available. There was variation in 
Table 3 Odds ratio of being HIV positive when cases consisted of non-IDUs

\begin{tabular}{|c|c|c|c|}
\hline & \multicolumn{3}{|l|}{ Adjusted odds ratio $\neq$} \\
\hline & All women & Black & White \\
\hline \multicolumn{4}{|l|}{ Age group } \\
\hline $20-24$ & $1.9(0.9$ to 4.1$)$ & 23.2 (3.3 to 165.2$) \dagger$ & $0.6(0.2$ to 2.1$)$ \\
\hline $25-29$ & $4.6(2.4$ to 8.8$) \dagger$ & 27.3 (4.5 to 164.8$) \dagger$ & $3.5(1.6$ to 7.4$) \dagger$ \\
\hline $30-34$ & $6.0(3.1$ to 11.4$) \dagger$ & 23.3 (3.9 to 140.3$) \dagger$ & $5.0(2.4$ to 10.3$) \dagger$ \\
\hline $35-39$ & $2.3(1.1 \text { to } 4.7)^{*}$ & $18.9(2.8$ to 128.2$) \dagger$ & $1.4(0.6$ to 3.4$)$ \\
\hline $40-59$ & 1.0 & 1.0 & 1.0 \\
\hline \multicolumn{4}{|c|}{ Lifetime number of sexual partners } \\
\hline 1 & 1.0 & 1.0 & 1.0 \\
\hline 2 & $1.8(0.8$ to 4.1$)$ & $2.2(0.6$ to 7.7$)$ & $0.7(0.1$ to 3.9$)$ \\
\hline $3-4$ & $4.6(2.2$ to 9.4$) \dagger$ & $8.7(2.6$ to 29.0$) \dagger$ & $3.1(1.0$ to 9.3$)$ * \\
\hline $5-9$ & $7.9(3.7$ to 16.6$) \dagger$ & $6.5(1.7$ to 24.4$) \dagger$ & $6.8(2.4$ to 19.5$) \dagger$ \\
\hline $10+$ & $20.4(9.6$ to 43.4$) \dagger$ & $6.0(1.1 \text { to } 31.4)^{*}$ & $14.5(5.1$ to 41.3$) \dagger$ \\
\hline \multicolumn{4}{|c|}{ Ever had a termination of pregnancy } \\
\hline No & 1.0 & 1.0 & 1.0 \\
\hline Yes & $1.2(0.8$ to 1.8$)$ & $0.6(0.3$ to 1.2$)$ & $1.6(1.0$ to 2.6$)$ \\
\hline \multicolumn{4}{|l|}{ Marital status } \\
\hline Currently married§ & 1.0 & 1.0 & 1.0 \\
\hline Cohabiting & $1.9(1.1 \text { to } 3.4)^{*}$ & $0.5(0.2$ to 1.8$)$ & $3.4(1.7$ to 6.8$) \dagger$ \\
\hline Widowed & $47.6(20.0$ to 113.1$) \dagger$ & $84.0(3.7$ to 1916$) \dagger$ & 55.1 (20.3 to 150$) \dagger$ \\
\hline Divorced & $1.7(0.8$ to 4.0$)$ & $0.7(0.1$ to 5.6$)$ & $3.0(1.2 \text { to } 7.7)^{*}$ \\
\hline Separated & $1.9(0.8$ to 4.3$)$ & $5.5(1.2 \text { to } 24.7)^{*}$ & $1.6(0.4$ to 6.3$)$ \\
\hline Single & $2.1(1.3$ to 3.3$) \dagger$ & $2.2(0.9$ to 5.4$)$ & $2.9(1.5$ to 5.5$) \dagger$ \\
\hline \multicolumn{4}{|l|}{ Social class } \\
\hline I-IIINM & 1.0 & 1.0 & 1.0 \\
\hline IIIM-V & $1.3(0.8$ to 2.0$)$ & $0.9(0.4$ to 2.3$)$ & $1.2(0.7$ to 2.2$)$ \\
\hline Other & $1.3(0.8$ to 2.2$)$ & $2.6(0.9$ to 7.1$)$ & $0.5(0.2$ to 1.3$)$ \\
\hline \multicolumn{4}{|l|}{ Area of residence } \\
\hline SE England $\mathbb{I}$ & 1.0 & 1.0 & 1.0 \\
\hline London & $8.3(4.6$ to 14.9$) \dagger$ & $23.9(4.1$ to 139.9$) \dagger$ & $5.9(3.1$ to 11.2$) \dagger$ \\
\hline Scotland & $2.0(0.9$ to 4.5$)$ & 0.1 & \\
\hline \multicolumn{4}{|l|}{ Ethnic group } \\
\hline White & 1.0 & & \\
\hline Black & 25.2 (15.6 to 40.8$) \dagger$ & N/A & $\mathrm{N} / \mathrm{A}$ \\
\hline Asian & $2.0(0.7$ to 5.2$)$ & & \\
\hline Other & $5.9(2.3$ to 15.1$) \dagger$ & & \\
\hline
\end{tabular}

the strength and significance of association between the factors investigated and HIV infection between IDUs and non-IDUs, black and white heterosexually infected women and IDUs with more or fewer than 10 sexual partners in their lifetime.

The generalisability of the results of this study to the population at large depends on how representative the study cases (selected from genitourinary medicine clinics) were of all HIV positive women in the population. The study cases were representative of all HIV positive women in Great Britain with respect to age and ethnic group and similar to all diagnosed HIV positive women in terms of exposure category.

As with all case-control studies this investigation is open to selection bias, particularly as it uses cases and controls selected from two different studies. Selection bias is avoided when the controls are representative of the population from which the cases are drawn. NATSSAL provided a unique opportunity to access data on sexual and other characteristics of a representative sample of the population in Great Britain. Therefore selection bias could have been introduced in this study only to the degree in which cases are not representative of all cases of HIV infection in England. Cases were obtained from the MRC Collaborative Study of HIV Women, who were recruited from STD clinics. The geographical location of the clinics reflects quite well, although not perfectly, the spread of HIV infection in the UK. Information was collected slightly earlier for controls than for most cases, but it is unlikely that the characteristics studied would have changed much in a couple of years. Of more concern perhaps, is the fact that cases were selected from STD clinics. Would that make them unrepresentative of all cases in Great Britain? Women with HIV infection have a relatively high risk of presenting to STD clinics, for three reasons. Firstly, there is a large overlap in the risk factors for acquiring HIV infection (via sex or IDU) and other sexually transmitted infections, such as practising unsafe sex, having large numbers of sexual partners and having sex for drugs. Secondly, other sexually transmitted infections increase the risk of transmission of HIV infection during intercourse with an infective partner. Finally, women with HIV infection have a higher frequency of some other sexually transmitted infections as a consequence of HIV disease. So women attending STD clinics are not representative of all women in the population (and this is not a problem for the study), but cases of HIV in STD clinics are likely to be a good sample of all women with HIV infection. Although acknowledging that some selection bia might have been introducing by selecting cases from STD clinics, we suggest that this is still a good source of cases, and NATSSAL is an appropriate and unique source of controls. The latter maybe more of a problem for women who are IDUs. This group is of course hard to study, and selecting HIV infected women from STD clinic attendees is likely to have overrepresented IDUs with risky sexual behaviour, or rather undersampled those without risky sexual behaviour, although a unbiased sample of HIV infected IDU users is difficult to envisage. Another limitation of this group is that they were classified as IDUs if they injected drugs and shared needles, and clearly some women might have injected drugs and not shared needles but shared syringes and recipients. We expect this last group to be small. The potential for this bias, and the fact that numbers were relatively small, could affect the interpretation of the results for IDUs. 
Table 4 Odds ratio of being HIV positive when cases consisted of IDUs

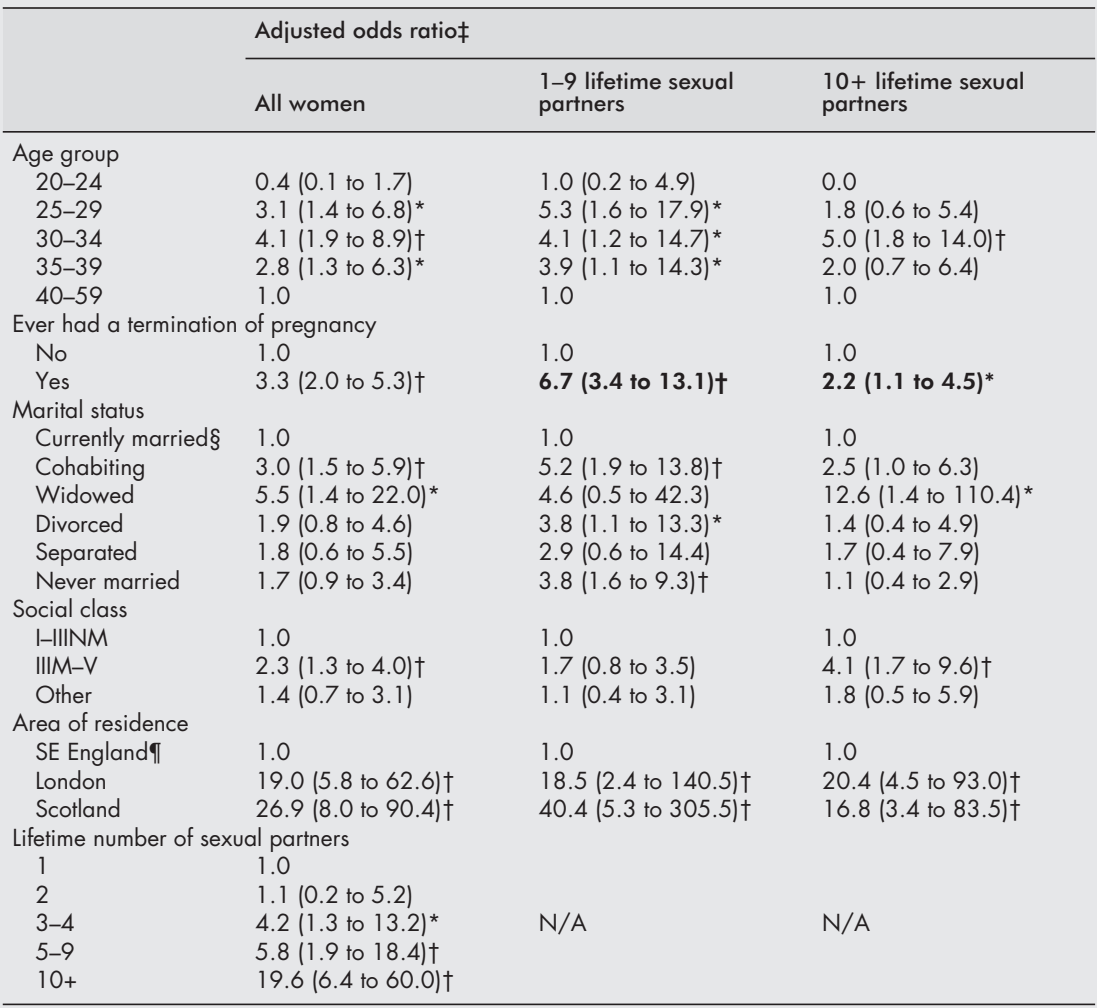

Cases are 94 HIV positive women who shared needles. * $p$ value $<0.05$; $\dagger p$ value $<0.005$; fadjusted for all the variables in the model; $\S$ currently married and living with spouse; ๆexcluding London. Figures in bold: $p$ value $<0.05$ for interactions with lifetime number of sexual partners.

The other type of bias, case-control studies are vulnerable to is information bias. Both studies used standardised questionnaires with very similar questions about the factors under investigation and there is no reason to expect any difference in recall or reporting bias in the cases and controls. The cases were subject to survival bias, as only women who survived until the time of the survey had a chance to be included in it. This bias will be kept to a minimum if the women who survived were no different, in terms of the variables under investigation, than those who died as a result of their HIV infection.

Number of partners, area of residence and widowhood were associated with HIV infection among all women, as well as among the subpopulations of IDUs and non-IDUs. Although numbers in these subpopulations were not large (making for a less stable model) there were quite a few statistically significant findings. It was not surprising that widowhood was associated with HIV infection, as widows include women who have lost their spouses to HIV. Among these women, widowhood is likely to be a consequence of HIV infection in their relationships. This endorses the importance of preventative strategies to be used within stable relationships and of partner tracing among HIV positive heterosexual and bisexual men. While one may expect that women who have been diagnosed as HIV positive to be more likely to be divorced or separated, there was less evidence of this in this investigation. This is possibly because a woman is more likely to be infected by her spouse than visa versa for biological, social, cultural, economical and epidemiological reasons. ${ }^{17-20}$ Thus if she is HIV positive, she is far more likely to be widowed than divorced or separated if her spouse was infected before her.

There were some differences between the factors that were associated with HIV infection for IDUs and non-IDUs. The association between widowhood and HIV infection is much greater among non-IDUs than IDUs. This is likely to be because non-IDUs have fewer additional HIV exposures besides sex with their partners, namely sharing needles and perhaps also sex for drugs or money. Being black was significantly associated with HIV infection among non-IDUs. In Great Britain, there is a higher proportion of AIDS cases reported among black African women than in the general population, ${ }^{21}$ suggesting that transmission is via sex rather than IDU. Being in a manual social class, ever having had a termination of pregnancy and residence in Scotland were significantly associated with HIV infection among IDUs, but not among non-IDUs.

Among non-IDUs, residence in London and widowhood were more strongly associated with HIV infection among black women than among white women. The strong association between residence in London and HIV infection among black women may be because migrants from high prevalence African countries are possibly more likely to settle in London where there is a large black African community. The UK black African population is highly concentrated (77\%) in London. ${ }^{22}$ Previous studies have proposed that the prevalence of HIV infection in London is mainly a reflection of the high levels of infection in women who have travelled to or migrated from Africa. ${ }^{23}{ }^{24}$ Complete data on country of birth and date of entry into the UK were not available, so ethnic group was used instead. Several studies have also shown that the risk of HIV infection is higher for women resident in urban areas (in England particularly London) than those resident in rural areas. ${ }^{152526}$ Among non-IDUs, young age was also more strongly associated with HIV infection among black women than among white women, while large numbers of sexual partners in ones lifetime ( 10 or more) was more strongly associated with HIV infection among white women.

Among IDUs there were different factors associated with HIV infection for women according to whether they had more 


\section{Key points}

- Different subpopulations of women have different risk factors and markers for HIV infection.

- The epidemiology of HIV infection in women can only be understood by identifying the factors associated with HIV infection.

- Prevention and control policies and activities for HIV/AIDS cannot treat all women as if they were the same.

or fewer than 10 sexual partners in their lifetime. Those with fewer than 10 sexual partners were significantly more likely to be single and have had a termination of pregnancy. Having a termination of pregnancy is likely to be an effect of HIV infection, as some women may have had termination of pregnancy because they knew of their HIV positive status. Those with 10 or more sexual partners were significantly more likely to be widowed and in a manual social class. Among IDUs, HIV transmission via needle sharing appears to be more important for women with fewer than 10 sexual partners in their lifetime and for women with more than 10 sexual partners, heterosexual transmission seems to pose a greater risk.

Identifying and knowing the importance of any factors associated with HIV infection for women is important for understanding the epidemiology of HIV in women. When targeting public health messages, it is equally important to recognise that women cannot be considered as a homogeneous group with respect to factors associated with HIV infection. In Great Britain, targeting all women collectively is not the best way to utilise resources for HIV prevention and control among women. Young black women, white women with multiple partners and IDUs with multiple partners should be targeted for education on sex safe sex practices. IDUs resident in London and Scotland should be targeted for education on avoidance of needle sharing. Finally, women resident in London should be made aware that they could be at a relatively high risk of HIV infection and thus be educated as to how they could limit their exposure to risk of infection.

While this study focused on women in Great Britain, the diversity of HIV risk factors and markers between subpopulations of women is also likely to be seen in other populations. Different subpopulations of women (for example, IDUS and non-IDUs, black and white women, women with more or fewer sexual partners) have different risk factors and markers for HIV infection. It is important to identify these differences so that women receive prevention and control messages that are appropriate to their HIV infection risk.

\section{ACKNOWLEDGEMENTS}

The authors wish to thank Anja Griffioen, Angus Nicoll, Judith Stephenson and Basia Zaba for their comments on an earlier draft of this paper and the ESRC for providing financial support to E V Boisson.

Thanks also to the participating centres and investigators in the MRC Collaborative Study Group: Anderson J, Melville R, Jeffries DJ, Norman J (St Bartholomew's Hospital), Welch J, Graham D, Fadojutimi M (King's College Hospital), Forster G, Philips M, Sampson K (The Royal London Hospital), Kitchen K, Wells C, Byrne G (St Mary's Hospital), Mercey DE, Allason-Jones E, Campbell L, French R, Woronowski H, Griffioen A, Stephenson JM, Phillips AN,
Keenlyside R, Johnson AM (Mortimer Market Centre), Barton S, Chard S, Sibley K, Mitchelmore M (Chelsea and Westminister Hospital), Bradbeer C, de Ruiter A, Hargreaves L, Doyle C (St Thomas's Hospital), O'Farrell N, Chappell J (Guys' Hospital), Johnson MA, Reid A, Farmer D, Saint N, Olaitan A, Madge S (The Royal Free Hospital), Russell J, Overington-Hickford L (Greenwich District Hospital), Brettle R, Morris S, O'Dornen P (City Hospital), Mulcahy F, Moseley J, Lyons F (St James's Hospital), Nayagam A, Edlin J (Royal Sussex County Hospital), Nayagam A (Southlands Hospital) and Tobin J, Tucker L, Harindra V (St Mary's Hospital).

\section{REFERENCES}

1 PHLS. AIDS and HIV-1 infection in the UK: monthly report. CDR 1999;9:235-6.

2 PHLS. AIDS and HIV-1 infection in the UK: monthly report. CDR 1995:5:13-16.

3 Quinn TC. Global burden of the HIV pandemic. Lancet 1996;348:99-106.

4 PHLS. AIDS and HIV-1 infection in the UK: monthly report. CDR 2000;10:149-60

5 Davies AG, Dominy NJ, Peters AD, et al. Gender differences in HIV risk behaviour of injecting drug users in Edinburgh. AIDS Care 1996;8:517-27

6 Gossop M, Powis B, Griffiths P, et al. Female prostitutes in south London: use of herion, cocaine and alcohol and their relationship to health risk behaviours. AIDS Care 1995;7:253-60.

7 Klee H. HIV risks for women drug injectors: heroin and amphetamine users compared. Addiction 1993;88:1055-62.

8 Donoghoe MC. Sex, HIV and the injecting drug user. Br J Addict 1992;87:405-16.

9 Nicolosi A, Leite MLC, Musicco M, et al. Parenteral and sexual transmission of human immunodeficiency virus in intravenous drug users: a study of seroconversion. Am J Epidemiol 1992;135:225-33.

10 Johnson AM, Wadworth J, Wellings K, et al, eds. Sexual attitudes and lifestyles. Oxford: Blackwell Scientific Press, 1994

11 Wadsworth J, Field J, Johnson AM, et al. Methodology of the National Survey Sexual Attitudes and Lifestyles. J R Stat Soc 1993;156:407-2 1.

12 The Study Group for the MRC Collaborative Study of HIV infection in Women. Ethnic differences in women with HIV infection in Britain and Ireland. AIDS 1996;10:89-93.

13 PHLS. HIV and AIDS quarterly surveillance tables. London: PHLS, 1996c.

14 Johnson AM, Wadworth J, Wellings K, et al. Sexual lifestyles and HIV risk. Nature 1992;360:410-12.

15 Unlinked Anonymous Surveys Steering Group. Prevalence of HIV in the United Kingdom. Summary of data to the end of 1998. London: Department of Health, 1999.

16 Norusis MJ. SPSS/PC+ Advanced statistics version 5.0. USA: SPSS, 1992.

17 Vuylsteke B, Sunkutu R, Laga M. Epidemiology of HIV and sexually transmitted infections in women. In: Mann J, Tarantola D, eds. AIDS in the world II. New York: 1996:97-109.

18 De Bruyn M. Women and AIDS in developing countries. Soc Sci Med 1992;34:249-62

19 Heise LL, Elias C. Transforming AIDS preventation to meet women's needs: a focus on developing countries. Soc Sci Med 1995:40:931-43.

20 Gupta GR, Weiss E. Women's lives and sex: implications for AIDS prevention. Cult Med Psychiatry 1993;17:399-412.

21 PHLS. AIDS and HIV-1 infection in the UK: monthly report. CDR 1996:6:251-4.

22 Owen D. Size, structure and growth of the ethnic minority populations. In: Coleman D, Salt J. Ethnicity in the 1991 census. Demographic characteristics of the ethnic minority populations. London: HMSO (OPCS), 1996:90-5.

23 Swan AV, Nicoll A, McGarrigle C, et al. An investigation assessing the fraction of HIV infection attributable to ethnic group variations in risk. Int J Epidemiol 1985;243 (suppl 1):S15-20.

24 Ades AE, Parker S, Cubitt D, et al. Two methods for assessing the risk factor composition of the HIV-1 epidemic in heterosexual women: Southeast England, 1988-1991. AIDS 1992:6:1031-6.

25 Wadsworth J, Hickman M, Johnson AM, et al. Geographic variation in sexual behaviour in Britain: implications for sexually transmitted disease epidemiology and sexual health promotion. AIDS 1996;10:193-9.

26 Barongo LR, Bordorff MW, Mosha FF, et al. The epidemiology of HIV-1 infection in urban areas, roadside settlements and rural villages in Mwanza region, Tanzania. AIDS 1992;6:1521-8. 